\title{
O CONTEÚDO JURÍDICO DO PRINCÍPIO CONSTITUCIONAL DA GARANTIA DE PADRÃO DE QUALIDADE DO ENSINO: UMA CONTRIBUIÇÃO DESDE A TEORIA DOS DIREITOS FUNDAMENTAIS ${ }^{1}$
}

\author{
Salomâo Barros Ximenes
}

\begin{abstract}
RESUMO: A Constituição estipula um conjunto de princípios do ensino, dentre eles a garantia de padrão de qualidade. $\mathrm{O}$ artigo analisa o sentido de tal previsão quanto à educação básica e estabelece um marco conceitual sobre o seu conteúdo normativo, com base na teoria dos direitos fundamentais como princípios, de Alexy. O princípio objetiva proteger a máxima qualidade do ensino em função das condiçôes fáticas e jurídicas existentes. A partir daí, propomos que os componentes do direito à qualidade sejam definidos sob o enfoque de direitos humanos, incluindo as obrigaçôes estatais de respeitar e proteger as liberdades na educação e de realizá-la em condiçóes de igualdade. $\mathrm{O}$ direito à qualidade compreende sete dimensóes jurídicas a serem contempladas nos processos de juridificação e de monitoramento.
\end{abstract}

Palavras-chave: Qualidade do Ensino. Direito à Educação. Direitos Fundamentais. Plano Nacional de Educação.

\section{THE LEGAL CONTENTS OF THE CONSTITUTIONAL PRINCIPLE OF QUALITY EDUCATION ASSURANCE: A CONTRIBUTION FROM THE THEORY OF FUNDAMENTAL RIGHTS}

ABSTRACT: The Constitution stipulates a set of principles for education, including the assurance of quality standards. This article analyzes the meaning of such provision regarding basic education and provides a conceptual framework on its normative content, based on the theory of fundamental rights as principles, by Alexy. The principle intends to protect the highest quality of education according to the existing factual and legal conditions. From that point, we propose that the components of the right to quality education should be defined under the human rights approach, including the state's obligations to respect and protect the freedoms in education and hold it on equal terms. The right to quality has seven legal dimensions to be included in the processes of legal regulation and monitoring.

* Universidade Federal do ABC, Centro de Engenharia, Modelagem e Ciências Sociais Aplicadas, São Bernardo do Campo, SP, Brasil. E-mail de contato: salomao.ximenes@ufabc.edu.br. 
Keywords: Quality of education. Right to Education. Fundamental Rights. National Education Plan.

\section{LE CONTENU JURIDIQUE DU PRINCIPE CONSTITUTIONNEL DE L'ASSURANCE-QUALITÉ DE L'ENSEIGNEMENT: UNE CONTRIBUTION DE LA THÉORIE DES DROITS FONDAMENTAUX}

RÉSUMÉ:La Constitution stipule un ensemble de principes pourl'enseignement, y compris l'assurance-qualité. L'article analyse la signification d'une telle prédiction concernant l'éducation de base et fournit un cadre conceptuel sur son contenu normatif, en fonction de la théorie des droits fondamentaux en tant que principes, celle d'Alexy. Le principe a l'intention principal de protéger la plus haute qualité de l'enseignement en fonction des conditions factuelles et juridiques existantes. De ce point, nous proposons que les composantes du droit à la qualité soient définies sous le regard de l'approche des droits de l'homme, y compris les obligations de l'État de respecter et de protéger les libertés dans l'éducation et de l'accomplir sur un pied d'égalité. Le droit à la qualité a sept dimensions légales à inclure dans la réglementation juridique de processus et de surveillance.

Mots-clés: Assurance-Qualité de l'Enseignement. Droit à l'éducation. Droits fondamentaux. Plan national d'éducation.

\section{Introdução}

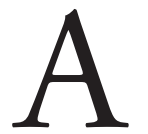

Constituição Federal brasileira estipula um conjunto de princípios a serem realizados na educação escolar, dentre eles a garantia de padrão de qualidade (CF/88, art. 206, VII). O artigo analisa o sentido de tal previsão quanto à educação básica e propóe um marco conceitual sobre o conteúdo normativo do direito à qualidade do ensino no Brasil.

A ideia de qualidade na educação sofre relevantes influxos na história da educação brasileira, como demonstram Celso Beisiegel (2006), Romualdo Oliveira e Gilda Araújo (2005). Para Beisiegel (2006), as proposiçóes sobre qualidade são consentâneas da noção de "má qualidade" da escola pública, que passou a ser difundida nas últimas décadas do século passado. Esse autor relaciona a ascensão do debate sobre a "má qualidade" ou "queda da qualidade" da escola pública à extensão das oportunidades educacionais para as classes populares e ao consequente desmonte progressivo dos mecanismos de seleção e exclusão que asseguravam a "qualidade" de uma escola pública seletiva e elitista.

Oliveira e Araújo (2005), a partir dessa proposição, demonstram como se deu a ascensão da noção de qualidade educativa nos últimos anos, caracteri- 
zada pela disseminação da aferição do desempenho dos estudantes em testes de larga escala. Para esses autores, a aferição do desempenho através desses testes e a disseminação dos seus resultados, que hoje hegemoniza o debate sobre qualidade educativa, ganhou espaço na medida em que não mais é possível verificar a qualidade dos sistemas de ensino unicamente sob os aspectos da exclusão e da repetência.

Almerindo Afonso (2009) também ressalta que a elevação do "padrão de qualidade" à posição de destaque alcançada nos dias atuais deve ser atribuída, principalmente, à crescente hegemonia conquistada pelos modelos de avaliação estandardizada, nascidos durante as reformas educacionais neoconservadoras dos países centrais. Outros autores, como Pablo Gentili e Tomaz da Silva (1995) destacam que a preocupação com a "qualidade", enquanto um fator específico do processo educacional, é explicada pela influência das mudanças nos processos produtivos industriais e pela adoção, inicialmente na esfera privada e em seguida na pública, da gestão por resultados e, principalmente, da concepção de gestão para a qualidade total.

Por outro lado, há quem visualize na proteção jurídica ao princípio da qualidade uma exigência de garantia de igualdade de base quanto às condiçóes de funcionamento das escolas (insumos) e à qualificação dos processos educacionais. É o caso de relevantes movimentos e organizaçóes que atuam em defesa da escola pública, como a Campanha Nacional pelo Direito à Educação. Esta, na formulação do Custo Aluno Qualidade (CAQ), propóe que a qualidade do ensino

[...] está associada à qualidade dos processos de ensino e aprendizagem, o que, por sua vez, se relaciona à qualidade dos insumos utilizados. Em outras palavras, a idéia central é que a garantia de insumos adequados seja condição necessária - ainda que não suficiente". (CARREIRA; PINTO, 2007, p. 25)

Portanto, em cada contexto e segundo cada posição, a ideia de "qualidade" mobiliza as mais diferentes concepçôes político-pedagógicas. Há quem reconheça nesse princípio expressão de uma agenda reducionista para a educação, um propósito de padronizar o trabalho escolar, eliminando-se a diversidade de processos e objetivos educacionais. Há quem interprete tal princípio como um chamamento à medição pública dos resultados educacionais e à responsabilização direta de professores, escolas e gestores em função do desempenho dos estudantes. Há também quem busque atribuir um significado igualitário ao princípio, no sentido de fortalecer a luta por direitos educacionais. Em meio a visóes tão distintas, seria possível propor uma resposta juridicamente mais adequada para a questão do conteúdo do princípio constitucional ou, pelo contrário, todas as opçôes de políticas públicas estariam igualmente ajustadas a este direito? Em outros termos: 
existe uma resposta "certa" para o conteúdo normativo do princípio constitucional de garantia de padrão de qualidade do ensino, ou essa é uma questão de mera discricionariedade de gestores e legisladores? $\mathrm{O}$ direito tem alguma utilidade na disputa de significados político-pedagógicos da "qualidade" ou é um mero instrumento de formalização de concepçôes hegemônicas em cada contexto?

Essas são questóes que nos remetem à diferença entre as dimensóes empírica e normativa dos estudos jurídicos. Compartilhamos, nesse aspecto, do enfoque proposto por Robert Alexy (2008) para o estudo dos direitos fundamentais no constitucionalismo democrático e social contemporâneo. Para esse autor, o direito como uma disciplina prática, ao mesmo tempo conectada a posiçóes morais, impôe a integração de três perspectivas da chamada "dogmática" jurídica: além da dogmática normativa, que tem como propósito fornecer respostas adequadas ao conteúdo de cada direito; há a dogmática analítica, que trata dos conceitos jurídico-políticos fundamentais e da estrutura do sistema jurídico, e a dogmática empírica, que é voltada ao conhecimento do direito positivo, da prática jurisdicional e de sua aplicação.

A dogmática normativa, portanto, não objetiva responder às instigantes questóes sobre como o princípio da qualidade vem sendo realizado na prática e como o direito vem sendo utilizado para isso. Seu objetivo é oferecer proposiçóes básicas sobre o conteúdo normativo de cada direito, com base nas quais passa a ser possível avaliar os processos de juridificação e as diferentes concepçóes em disputa. O problema da dogmática normativa decorre, principalmente, do caráter semanticamente aberto dos princípios constitucionais, como a própria qualidade.

Os princípios de direitos fundamentais são, nessa concepção, expressão do arranjo jurídico-institucional possível no Estado Social e Democrático de Direito contemporâneo. O constitucionalismo que legitima esse Estado é, por definiçáo, complexo e aberto às diferentes concepçóes de qualidade do ensino que buscam alcançar hegemonia na sociedade. Por esse motivo, como previne Alexy (2008), a resposta sobre qual deveria ser o conteúdo de um determinado direito fundamental sempre incluirá as valorações de quem resolve a questão. Essa é a razão pela qual o autor defende a complementaridade necessária entre as abordagens normativa e analítica, já que esta última permite a quem estuda um determinado direito estabelecer as bases a partir das quais constrói sua argumentaçấo. Isso significa que, do ponto de vista normativo, não só é possível como é necessário responder racionalmente à questão sobre o conteúdo do princípio constitucional inscrito no inciso VII do art. 206.

$\mathrm{Da}$ articulação entre as dimensóes empírica, normativa e analítica da dogmática jurídica fica evidente que as opçôes políticas e legislativas nunca devem ser entendidas como meramente técnicas, mas como resultado do conflito de posiçóes que se apoia em um amplo espaço de juridicidade dos princípios cons- 
titucionais. É nesse sentido que devem ser analisadas as opçôes hegemônicas de juridificação presentes no atual impulso ao reconhecimento jurídico da qualidade do ensino.

\section{Novo Plano Nacional de Educação (PNE) e agendas de juridificação dos aspectos relacionados à qualidade da educação básica}

Vivenciamos no país um forte impulso à regulação jurídica da qualidade da educação básica, que se manifesta tanto na disseminação como na complexificação das ferramentas de juridificação utilizadas no campo educacional ${ }^{2}$. Prova disso é a grande relevância que o tema alcançou no novo PNE (Lei ${ }^{\circ}$ 13.005/2014), com expectativa de que siga no centro das discussóes durante os processos de regulamentação do direito e da política educacional, previstos no próprio PNE. Este, longe de significar o esgotamento de um ciclo de regulamentação do direito à educação, abre uma nova etapa de proteção jurídica e de planejamento público para sua efetivação, com a previsão de edição de novas normas, além de revisão e adequação de políticas em curso.

Sobre as políticas de promoção e garantia da qualidade da educação básica, o PNE carrega em seu texto diferentes visōes, por vezes, contraditórias e potencialmente incompatíveis. De um lado, a Meta 7 do PNE formaliza legalmente, enquanto política de Estado - no sentido atribuído por Maria Paula Bucci (2006) -, as metas nacionais de desempenho no Ideb, previamente estipuladas pelo governo no âmbito do Plano de Metas Compromisso Todos pela Educação (Decreto $n^{\circ}$ 6.094/2007). O Índice de Desenvolvimento da Educaçâo Básica (Ideb) é assim fortalecido, com a pretensão que venha a se consolidar não apenas como um indicador, mas como um eixo estruturante das políticas de promoção da qualidade a serem promovidas.

É a partir dos resultados estipulados na Meta 7 que se desdobram importantes estratégias, como a que estipula o estabelecimento e implantação de diretrizes pedagógicas para a educação básica e da Base Nacional Comum dos currículos, articulada aos chamados "direitos e objetivos de aprendizagem e desenvolvimento dos(as) alunos(as)" (7.1), a serem progressivamente alcançados (7.3). O Plano também determina a adoção de estratégias de incentivo para o alcance das metas no Ideb por Estados e Municípios (7.9), bem como o estabelecimento de "políticas de estímulo às escolas que melhorarem o desempenho no Ideb, de modo a valorizar o mérito" (7.36).

Ao mesmo tempo em que enfatiza a dimensão dos resultados educacionais, a própria Meta 7 incorpora estratégias que levam a uma noção mais ampla 
de qualidade educativa. É o caso da Estratégia 7.3, que, articulada às diretrizes legais para criação do Sistema Nacional de Avaliação da Educação Básica (Sinaeb), busca incorporar indicadores de avaliaçáo institucional - perfil dos alunos e dos profissionais da educação, infraestrutura e recursos pedagógicos, gestão etc. -, além dos indicadores de rendimento escolar já implantados (Lei n 13.005/2014, art. $\left.11, \$ 1^{\circ}, \mathrm{II}\right)$.

O novo PNE também reforça a dimensão normativa da qualidade que enfatiza a necessidade de assegurar insumos educacionais básicos em todas as escolas, nos termos em que a LDB define os "padróes mínimos de qualidade do ensino" (Lei n ${ }^{\circ} 9.394 / 1996$, art. $4^{\circ}$, IX). É nesse sentido que a Estratégia 7.21 determina o estabelecimento por parte da União, em regime de colaboração, dos Parâmetros Mínimos de Qualidade dos Serviços da Educação Básica. Nas Estratégias 20.6 a 20.8 e 20.10, vinculadas à meta de elevação substancial dos dispêndios públicos em educação pública até o patamar de 10\% (dez por cento) do PIB, a dimensão relativa aos insumos e condiçóes básicas de funcionamento é conectada às políticas de financiamento, através do mecanismo do CAQ, cuja definição e implementação progressiva devem ser antecedidas da implementação do CAQ inicial (CAQi). Por fim, o PNE estipula a aprovação de uma "Lei de Responsabilidade Educacional, assegurando padrão de qualidade na educação básica, em cada sistema e rede de ensino, aferida pelo processo de metas de qualidade aferidas por institutos oficiais de avaliaçâo educacionais" (20.11).

Em suma, com a Base Nacional Comum, os Parâmetros Mínimos de Qualidade, o CAQ e a Lei de Responsabilidade Educacional, o PNE 2014-2024 estipula 4 (quatro) agendas de juridificação expressamente articuladas à definição do conteúdo do direito à qualidade da educação básica, em sua dimensão prática (empírica). O prazo para que ocorram tais regulamentaçóes varia entre 1 (um) e 3 (três) anos, o que indica uma intensa atividade legislativa sobre o tema no próximo período.

Vê-se, portanto, que a aprovação do novo PNE consolida movimento que já havia sido apontado no trabalho de Araújo e Oliveira (2005), que caracterizaram a regulação do padrão constitucional de qualidade como uma nova dimensão de luta pelo direito à educaçáo no País. Uma dimensão de luta, destacamos, que não está isenta de desacordos relevantes sobre o conteúdo prioritário que deve ser atribuído àquele princípio constitucional. Há diferentes vertentes de juridificação em disputa, tanto em relação ao conteúdo do direito à qualidade quanto aos meios e incentivos disponibilizados para sua garantia, cada uma delas significando a pretensão hegemônica de determinada concepção política e pedagógica.

Percebe-se, daí, que o estudo dos rumos do que denomino processo de juridificação do padrão de qualidade do ensino está diretamente relacionado ao sentido da necessária reconfiguração do direito humano fundamental à educação, 
ainda excessivamente vinculado às agendas de acesso e permanência e pouco capaz de responder aos novos desafios. Avaliar os rumos desse processo e em que medida realiza o direito humano em questão, no entanto, requer o prévio estabelecimento de um marco normativo sobre o conteúdo desse direito, sob pena de se reduzir o direito em si aos aspectos que, em um determinado contexto jurídico-político, alcançam hegemonia através do processo legislativo. É necessário, portanto, recorrer a uma teoria dos direitos fundamentais e, mais especificamente, a uma teoria normativa sobre o conteúdo jurídico do direito à qualidade do ensino no Brasil.

\section{A qualidade do ensino como um princípio: significado político-jurídico na teoria dos direitos fundamentais}

Uma das principais inovaçóes da Constituição de 1988 na seção dedicada à educação é a inserção de um artigo específico destinado aos princípios do ensino. Nos textos constitucionais anteriores, quando presentes, alguns desses princípios eram parte de artigos dedicados às regras de organização de níveis e etapas escolares ou de deveres estatais específicos. O princípio da garantia de padrão de qualidade do ensino, por sua vez, é inédito em todos os sentidos, já que essa preocupaçáo sequer constava nos textos constitucionais anteriores, como demonstrado por Marcelo Furtado (2009).

Há um significado político-jurídico para essa nova configuração. A Constituição de 1988 é típica do Estado Social e Democrático de Direito ${ }^{3}$, nascido das experiências revolucionárias do primeiro pós-guerra, que marcaram o início do século XX. As Constituiçóes típicas desse modelo estatal são expressão formal de um novo tipo de arranjo político e social, de um novo tipo de "pacto assimétrico". (VIEIRA, 2013) Um "pacto" que não significa um compromisso genuíno em termos de princípios e objetivos coletivos, mas pode ser mais bem representado como "um arranjo domesticador do antagonismo de classes que segue inscrito no sistema econômico". (HABERMAS, 1999, p. 495) Fruto da vitória da vertente socialista reformista, contra monarquistas e conservadores de um lado e comunistas revolucionários de outro, a Constituição Alemã de 1919 - que funda a estrutura de proteção constitucional do direito à educação incorporada às constituiçóes democráticas do Brasil a partir do texto de 1934, como demonstrado por Carlos Jamil Cury (1998) - expressava esse arranjo.

Os princípios constitucionais cumprem um papel decisivo nesse modelo de Estado, já que possibilitam e fortalecem a adesão ao pacto assimétrico expresso na Constituição ao nela incorporar demandas de progresso social e econômico das classes populares. Em sentido inverso ao que lhes atribuem os críticos e o senso comum, a abertura, o simbolismo ou a indeterminação que caracterizariam os princípios de direitos fundamentais são, na realidade, seu principal valor. 
A assimetria e a conflituosidade características da Constituição de 1988 são também perceptíveis na seção dedicada à educação. Os princípios constitucionais do ensino são bases para desacordos amplos quanto aos seus respectivos conteúdos e, ao mesmo tempo, expressóes de compromissos elementares de realizaçáo, no caso estudado, de realizaçáo da qualidade em alguma medida a ser posteriormente delimitada. O essencial é que os valores e propósitos inscritos nesses princípios estão na base do arranjo constitucional e são condição de legitimidade política.

É em função do ecletismo e da abertura do texto constitucional que diferentes campos políticos se reconhecem como destinatários dos bens jurídicos ali protegidos e, portanto, exercem pressáo legítima para a sua implementação, seja diretamente ou mediante regulamentação.

Esse fenômeno ganha objetividade, por exemplo, nas disputas em torno da destinação dos recursos públicos para a educação, que opõem os movimentos em defesa da escola pública ao setor privado, organizado em suas entidades representativas, que buscam ampliar o repasse de recursos públicos para suas instituiçôes. Tais movimentos são politicamente divergentes, representam setores politicamente antagônicos, portanto, sem possibilidade objetiva de uma composição que venha a maximizar mutuamente os seus interesses, ainda assim, a sobreposição conjuntural de um interesse sobre outro, em um determinado contexto, não significa quebra do arranjo constitucional.

As disputas por hegemonia política passam a ter como arena privilegiada o próprio texto da Constituição, enquanto dimensáo jurídica de regulaçáo do Estado e da sociedade. Em outras palavras: as disputas sobre o texto constitucional passam a ser meio privilegiado de ação política nas sociedades complexas juridicamente reguladas ${ }^{4}$ - disputa que se dá não sobre o sentido geral da Constituição, mas sobre o conteúdo normativo de cada princípio constitucional, como bem expressam as diferentes vertentes de juridificação da qualidade que buscam materializar o inciso VII do art. 206, já comentadas.

A constitucionalização dos princípios é, portanto, a maior expressão da resposta jurídico-institucional ao tipo de arranjo conflitivo que está na base do Estado Social e Democrático de Direito. Os princípios são a fonte do ideal de progresso jurídico inscrito nos pactos constitucionais de inspiração social-democrata. Nessa vertente de análise, o modelo teórico mais difundido no Brasil é aquele proposto na teoria dos direitos fundamentais como princípios, de Robert Alexy (2008).

Em termos gerais, para esse autor, o reconhecimento constitucional dos direitos fundamentais materializa-se na forma de princípios, caracterizados como "mandamentos de otimizaçáo" do sistema jurídico. Para Alexy (2008), os princípios não são meras diretrizes hermenêuticas ou normas cuja eficácia depende 
de complementação, também não são normas meramente simbólicas, mas sim normas originalmente dotadas de relevância prática e de aplicabilidade imediata.

Nessa proposição teórica, as normas jurídicas se dividem entre regras e princípios, cuja diferença é a "estrutura dos direitos que essas normas garantem". (SILVA, 2011, p. 45) Enquanto as regras garantem direitos, ou impóem deveres definitivos $^{5}$, os princípios estipulam tais direitos ou deveres prima facie. Essa diferença estrutural condiciona formas distintas de aplicação. A proposição básica de toda a teoria é assim sintetizada:

O ponto decisivo na distinção entre regras e princípios é que os princípios são normas que ordenam que algo seja realizado na maior medida possível dentro das possibilidades jurídicas e fáticas existentes. Princípios são, por conseguinte, mandamentos de otimizaçâo, que sâo caracterizados por poderem ser satisfeitos em graus variados e pelo fato de que a medida devida de sua satisfação não depende somente das possibilidades fáticas, mas também das possibilidades jurídicas. $\mathrm{O}$ âmbito das possibilidades jurídicas é determinado pelos princípios e regras colidentes.

Já as regras são normas que são sempre ou satisfeitas ou não satisfeitas. Se uma regra vale, entáo, deve se fazer exatamente aquilo que ela exige; nem mais, nem menos. Regras contêm, portanto, determinaçóes no âmbito daquilo que é fática e juridicamente possível. Isso significa que a distinção entre regras e princípios é uma distinção qualitativa, e não uma distinçáo de grau. Toda norma é ou uma regra ou um princípio. (ALEXY, 2008, pp. 90-91)

Enquanto a regra jurídica impóe a realização plena de seu comando, caso seja aplicável ao caso concreto; dos princípios não se espera a realização total daquilo que a norma exige, já que esta estipula um comando de maximização. Ao contrário, em situação de normalidade, sua realização será parcial, uma vez que incorpora diretivas amplas de justiça social e econômica, além de objetivos sociais ainda não alcançados. Determinante na caracterização dos princípios de direitos fundamentais como direitos prima facie, náo definitivos, é a ideia de que devem ser entendidos como mandamentos de otimização, com âmbito de proteção máximo. Ou seja, em contrapartida a não serem determinaçóes específicas, caracterizam-se como mandamentos de otimização, cuja especificação de conteúdo requer intenso trabalho de sopesamento e justificação. $\mathrm{O}$ essencial é que o direito prima facie estipulado no princípio é direito em si, dotado de força normativa e eficácia, ainda que sua aplicabilidade seja modulável em face das condiçóes jurídicas e fáticas existentes em cada contexto ${ }^{6}$. 
Como explica Virgílio da Silva (2011) a partir da lição de Alexy, há um longo caminho entre o que o princípio garante ou impóe prima facie e aquilo que é garantido ou imposto definitivamente no processo de concretização. Esse caminho é comumente trilhado através da especificação legislativa e das políticas públicas, mas também pelo Judiciário. Uma vez que se admite o caráter amplo do âmbito de proteção dos direitos fundamentais em si, a questão central a partir da teoria dos princípios é estabelecer critérios normativos e técnicas de interpretação que permitam enfrentar os conflitos entre pretensóes opostas, veiculadas em princípios de direitos fundamentais, estabelecendo padróes legítimos de restrição, delimitação e compatibilização.

É considerável o potencial explicativo dessa teoria na realidade constitucional brasileira, especificamente no estudo dos princípios jurídicos específicos - como os princípios do ensino (CF/88, art. 206) -, já que dá uma explicação coerente e aceitável para o tortuoso caminho entre os direitos fundamentais prima facie e sua especificação. Esse caminho será sempre um processo de restrição ou de delimitação de pretensões e expectativas a partir das condiçóes fáticas (blocos políticos hegemônicos, ideologias, recursos financeiros e humanos, técnicas disponíveis etc.) e jurídicas (limites jurídico-institucionais presentes na própria Constituição, colisão com outros direitos fundamentais etc.) enfrentadas no contexto específico em que decidem os poderes do Estado.

Por ora, no espaço deste trabalho, importa extrair dessa teoria as implicações de seu elemento essencial: os princípios são mandamentos de otimização, ou seja, são normas que exigem realizaçâo na maior medida possível, consideradas as possibilidades fáticas e jurídicas existentes. Essa concepção leva-nos necessariamente à adoção da perspectiva do suporte fático amplo dos direitos fundamentais, conforme explica Silva (2011). O suporte fático dos direitos fundamentais diz respeito, primeiramente, à definição dos bens - atos, fatos, estados ou posiçóes jurídicas - protegidos na norma, ou seja, ao chamado âmbito de proteção de cada direito. Adotar uma perspectiva de suporte fático amplo, portanto, exige incluir

[...] nesse âmbito [de proteção] toda ação, fato, estado ou posição jurídica que tenha qualquer característica que, isoladamente considerada, faça parte do 'âmbito temático' ou do 'âmbito da vida' de um determinado direito fundamental”. (SILVA, 2011, p. 72-73)

Significa, portanto, não excluir ou limitar previamente qualquer pretensão de ver protegido determinado bem no âmbito de proteção do direito em questão. Essa proposição é a que melhor responde à diversidade de dimensôes da qualidade do ensino, todas merecedoras de atenção se o que se espera é a maximização da efetividade dos princípios e fins da educação e não apenas estabelecer 
patamares mínimos de realização, que venham a se confundir com o próprio conteúdo do direito.

\section{O conteúdo jurídico do princípio constitucional da garantia de padrão de qualidade do ensino}

A maior dificuldade enfrentada por quem pretende definir o direito à educação de qualidade é estabelecer critérios válidos para uma proposição normativa sobre o seu conteúdo. Nesse ponto, nossa perspectiva teórica, fundada na teoria dos direitos fundamentais como princípios, mostra-se uma vantagem metodológica.

Podemos concluir a partir do exposto que o direito à qualidade do ensino, protegido na estrutura normativa de um princípio de maximização, guarda em seu âmbito de proteção toda e qualquer pretensão, ação ou requisito que, isoladamente considerado, poderia ser incluído nos conceitos "qualidade do ensino" e "padrão de qualidade do ensino" . A questão de fundo, no entanto, aparentemente se manteria. Afinal, o que faz parte do "âmbito temático" ou "da vida" do direito à qualidade do ensino? Mantém-se a questâo central, é verdade, mas se alteram os instrumentos de que dispomos para respondê-la.

Um enfoque tradicional ancorado nos pressupostos do positivismo jurídico procuraria a resposta nas regras que, em um contexto jurídico específico, estabelecem direitos específicos relacionados à qualidade, definindo este direito a partir daquelas regras específicas. Propomos perspectiva inversa para o estudo do princípio constitucional, ou seja, definir o seu conteúdo jurídico a priori, para só a partir daí analisar o resultado dos processos de restrição ou delimitação do direito à qualidade.

É errado do ponto de vista que adotamos - o princípio da qualidade do ensino como uma norma de direito fundamental - tomar as regras positivas nacionais como determinantes exclusivas do conteúdo jurídico da qualidade. Em outras palavras: não se pode reduzir o âmbito de proteção do princípio constitucional (que é parte do direito humano à educação) unicamente ao direito que se materializa em regras jurídicas objetivas. Essas regras são, na realidade, manifestações (empíricas) do direito definitivo - no sentido que a teoria dos princípios atribui a essa categoria -, portanto, são passíveis de avaliação, de monitoramento e de controle de constitucionalidade. Essas regras são o resultado inacabado e falho do processo de juridificação dos aspectos relacionados à qualidade do ensino e é nessa perspectiva que propomos que sejam estudadas, avaliadas e, eventualmente, juridicamente contestadas em razão de violações ao direito humano à educação. 
Falamos em vantagem metodológica dessa perspectiva por três motivos. Primeiro, porque a pergunta sobre o conteúdo jurídico do princípio da qualidade do ensino não parte, de início, de uma preocupação necessariamente restritiva e delimitadora, como fazem as abordagens tradicionais que se ancoram nas ideias de mínimo existencial ou de conteúdo absoluto do direito. A vantagem do princípio de direito fundamental, como demonstramos, é justamente a amplitude de bens, interesses, pretensóes e posiçóes jurídicas que legitimamente podem ser incluídas em seu conteúdo a priori.

Outra vantagem daí decorrente é a necessária abertura dos órgãos de produção jurídica à interdisciplinaridade. Com as ideias de "âmbito temático" ou "âmbito da vida", abre-se a composição do conteúdo semântico do princípio a um conjunto plural de intérpretes. Esse conteúdo deve ser objeto de discussão e de legitimação na interpretação específica de cada direito, em trabalho necessariamente interdisciplinar. Nesse sentido, a juridificação de aspectos relacionados ao respeito, à proteção e à realização do direito à qualidade do ensino, como um direito fundamental, é absolutamente dependente da incorporação de conhecimentos, práticas, deliberaçóes e proposiçóes do próprio campo educacional. Sua especificação deve ser, como decorrência, prioritariamente atribuída aos órgãos normativos dos sistemas de ensino, como os conselhos e as instâncias de democracia participativa do campo educacional.

A terceira vantagem diz respeito à compatibilidade entre essa perspectiva geral sobre o conteúdo dos princípios constitucionais e os esforços que vem sendo empreendidos para estabelecer um marco normativo ampliado sobre o direito humano à educação.

\section{O conteúdo do princípio constitucional sob o enfoque de direitos humanos educacionais}

Conforme já registramos, tanto na perspectiva da evolução das demandas sociais por direito à educação como na definição do conteúdo jurídico específico desse direito nas agendas de juridificação em curso - veja-se o novo PNE -, a exigência de qualidade educativa passa a ser uma constante. A qualidade, em suas diferentes acepçôes, destaca-se em muitas dessas proposiçôes político-jurídicas em oposição às limitaçóes teóricas e empíricas do direito à educação unicamente às suas dimensóes formais, relacionadas à oferta, ao acesso e à permanência na escola. Podemos então concluir que a adoção de perspectiva maximizadora sobre o princípio da qualidade do ensino significa não excluir previamente essa dimensão do âmbito de proteção imediato do direito à educação - normalmente identificado à luta por acesso -, e não limitar o conteúdo jurídico desse princípio a aspectos considerados mínimos ou a apenas algumas de suas dimensóes, escolhidas por 
razóes de pragmatismo técnico ou governamental, por interesse de atores privados ou apoiadas no mero senso comum.

Nesse ponto, o âmbito de proteção ampliado do direito à qualidade e sua aplicabilidade imediata ganham amparo na normativa internacional de direitos humanos, mais especificamente no Pacto Internacional de Direitos Econômicos, Sociais e Culturais (PIDESC), ratificado pelo Brasil (Decreto ${ }^{\circ}$ 591/1992), cuja determinação básica é plena e expressamente compatível com a perspectiva maximizadora do âmbito de proteção de tais direitos. Vejamos:

Art. ${ }^{\circ}$. 1. Cada Estado-parte no presente Pacto compromete-se a adotar medidas, tanto por esforço próprio como pela assistência e cooperação internacionais, principalmente nos planos econômico e técnico, até o máximo de seus recursos disponiveis, que visem assegurar, progressivamente, por todos os meios apropriados, o pleno exercício dos direitos reconhecidos no presente Pacto, incluindo, em particular, a adoção de medidas legislativas [grifo nosso].

É o Pidesc, portanto, que possibilita demonstrar a transposição das proposiçóes teóricas já apresentadas para o plano do direito positivo. Com base no PIDESC, a referência de progresso passa a ser a proximidade entre o direito realmente protegido, após sopesamento e aplicação, e o direito prima facie. Mais que a mera demonstração objetiva de que não houve retrocesso ou do eventual progresso obtido em termos absolutos, a perspectiva dos direitos fundamentais conforme a teoria dos princípios - exigiria uma justificação mais ampla, ou seja, a demonstração das condiçóes fáticas e jurídicas impeditivas de progressos ainda maiores. (PIDESC, arts. 16, 1; 17, 2) Essa proposição é plenamente compatível com o dispositivo jurídico acima transcrito, que impóe aos Estados a adoção de medidas com o máximo de recursos disponíveis e até o pleno exercício dos direitos. Ou seja, ao estender o enfoque avaliativo sobre a eficácia do direito, o PIDESC coloca em prática o princípio da máxima efetividade dos direitos fundamentais protegidos - princípio aplicável no âmbito interno por força da integração de regimes do $\$ 2^{\circ}$ do art. $5^{\circ}$ da Constituição.

A exigência de padrão de qualidade como norma maximizadora é, ademais, além de teórica e metodologicamente justificável, uma decorrência axiológica da própria prescrição jurídica de fins públicos para a educação, previstos de forma ampla na Constituição de 1988 (art. 205) e, principalmente, nos tratados internacionais de direitos humanos ${ }^{8}$. A qualidade, nesse sentido, é expressão da dimensão interna (material) do ensino, ou seja, das condiçóes de oferta, da gestão e dos processos educativos responsáveis por assegurar que tais fins ou resultados relevantes sejam alcançados. Sem esses requisitos, ainda que se universalizem disponibilidade e acesso, terá fracassado a educação enquanto bem público universal 
e enquanto direito fundamental de dimensão coletiva. É, portanto - ao lado da dimensão externa (formal) representada pelo acesso e pelos dados de permanência e conclusão -, também conteúdo característico do direito humano à educação.

Entendemos, nesse ponto, que a ideia de mandamento de otimização que caracteriza os direitos fundamentais se refere a diferentes posiçóes, bens e objetivos dos quais se espera maximização. Não diz respeito somente a cada direito tomado como um todo, mas também a cada componente desse direito.

Em relação especificamente aos componentes do direito humano à educação escolar, tomamos como base as características amplas desse direito, inicialmente definidas por Katarina Tomasevski (2006) e incorporadas à interpretação oficial do Comitê de Direitos Econômicos, Sociais e Culturais da ONU, na Recomendação no 13 , de 1999 . Nesse sentido, o mandamento de otimização da disponibilidade visa à universalização da educação obrigatória e à generalização da educação não obrigatória. A acessibilidade busca maximizar a igualdade de condiçóes para o acesso e permanência em todos os níveis e etapas escolares. A aceitabilidade, por sua vez, busca maximizar a relevância, a adequação e a qualidade do ensino; enquanto a adaptabilidade tem como objetivo maximizar as liberdades no ensino e o pluralismo de concepçóes pedagógicas, sua flexibilidade e capacidade de responder às necessidades e expectativas das sociedades e comunidades, respeitando e promovendo sua diversidade.

O direito à educação em sentido amplo, assim, sob a base dos direitos humanos fundamentais reconhecidos na extensa normativa internacional, extrapola as dimensóes imediatas relativas à disponibilidade de vagas e à acessibilidade à escolaridade obrigatória, exigindo o adensamento de conteúdos normativos relativos às características aceitabilidade e adaptabilidade. Por conseguinte, envolve normas que protegem o direito à educaçáo (direito a acessar escolas de boa qualidade e sem discriminação), mas também normas que veiculam direitos humanos na educaçáo (ou seja, o respeito aos direitos humanos no processo educacional) e através da educaçáo (nesse caso, identificando a educaçáo como um meio prioritário de difusão dos direitos humanos fundamentais).

A qualidade do ensino diz respeito a cada um desses enfoques sobre o direito à educação em seu sentido amplo. Protege-se a qualidade no direito à educação quando se estabelecem normas e políticas voltadas à garantia do direito às condiçóes básicas de funcionamento das escolas, mas também quando se incorpora a dimensão dos resultados educacionais, nesse caso, como parte do direito de todos ao desenvolvimento e à aprendizagem de conteúdos socialmente relevantes. Ainda que esses enfoques, baseados nas condiçóes e nos resultados do processo de escolarização, sejam fundamentais para uma educação de qualidade, esta não se realiza desconsiderando as demais, ao menos não em uma perspectiva de direitos humanos. 
Daí que a exigência de direitos humanos na educação remete aos princípios da liberdade no ensino, do pluralismo e da participação (CF/88, art. 206, incisos II, III e VI, respectivamente) - princípios que também exigem realização máxima, dentro das condiçôes fáticas e jurídicas existentes. Liberdade pedagógica e de aprendizagem, mas também liberdade como direito dos estudantes, sobretudo, a serem respeitados e a se verem livres de maus tratos, humilhaçôes, discriminações, puniçōes corporais e violências simbólicas. São, portanto, um conjunto de liberdades no ensino que compóem o suporte fático do direito à educação em sentido amplo. Esse conjunto de liberdades, uma vez delimitado, constitui-se como barreira contra a intervençáo abusiva do Estado, contra concepçóes de qualidade excessivamente centralizadas e padronizadas. Da mesma forma, o pluralismo pedagógico e a exigência de participação na gestão da educaçấo são balizas para a observação dos direitos humanos na educação, uma vez que determinam que uma parcela do conteúdo da qualidade deve ser definida em processos participativos e de auto avaliação escolar.

É através da ponderação exigida por esses princípios que se pode buscar um equilíbrio nas normas jurídicas, entre as exigências gerais de igualdade do direito à educação e as diferentes necessidades e demandas legítimas de reconhecimento, bem como aspiraçôes, ideias e projetos de escolas, professores, estudantes, correntes político-pedagógicas e grupos sociais. $\mathrm{O}$ equilíbrio se dá quando o pluralismo, o reconhecimento e a participação não redundam na reprodução das desigualdades, mas possibilitam ampliar a concepçâo de justiça educacional em direção a uma perspectiva bidimensional de "redistribuição somada ao reconhecimento". (PIOVESAN, 2008, p. 50) São, portanto, princípios que permitem afirmar a diversidade na igualdade, equilibrando a aplicação prática do princípio da garantia de padrão de qualidade.

Como ponto fundamental nessa dimensão, a realização dos direitos humanos na educação coloca no centro das preocupaçôes a relevância do processo educacional conforme esses direitos. Não bastam as condiçóes de ensino-aprendizagem - ainda que estas sejam condição indispensável -, muito menos bastaria demonstrar alto desempenho relativo em testes padronizados ou "rankings" locais, nacionais ou internacionais, uma vez que o processo que levou das condiçóes iniciais aos resultados é igualmente relevante enquanto dimensão do direito à qualidade do ensino. Em muitos casos, opçôes restritivas em termos de resultados educacionais podem ter como consequência retrocessos no processo educacional, diminuindo-se a proteçấo aos direitos humanos na educação e, consequentemente, a proteção às liberdades, ao pluralismo e à gestão democrática educacional.

O direito à educação enquanto exigência de direitos humanos através da educação, por sua vez, coloca em relevo a complementaridade que se estabelece entre educação escolar e outros direitos fundamentais. A normativa internacional dá grande destaque aos propósitos educacionais, ou seja, ao conjunto de valores 
e atitudes a serem compartilhados pelos indivíduos ao redor do mundo e através da educação. Também a chamada "educação para a cidadania", um dos propósitos desse direito na Constituição brasileira, destaca as elevadas expectativas que historicamente foram colocadas na educação em sentido amplo.

Sobre esse aspecto, destacamos a complementariedade entre gestão democrática da educação e formação para o exercício da cidadania. As exigências normativas de participação na gestão e na definição do projeto político-pedagógico das escolas devem ser compreendidas tanto na perspectiva processual como na dos resultados esperados. Haveria, no mínimo, uma “incoerência de se 'ensinar' conteúdos que visem a um comportamento democrático, por meio de relaçóes autoritárias", como destaca Vitor Paro (2000, p. 223). Esse autor nos evidencia que, ao menos em relação aos resultados esperados de uma educação de qualidade que sejam fortemente determinados por valores e princípios de cidadania, "[...] na relação pedagógica, o método é também conteúdo”. (PARO, 2000, p. 223)

Portanto, as expectativas sobre a promoção dos direitos humanos na e através da educação possuem implicaçóes diretas no conceito de qualidade e, por conseguinte, nos direitos relacionados, extrapolando-se as limitadas dimensóes jurídicas comumente identificadas ao conteúdo imediato do direito à educação. Significam, sobretudo, uma ampliação do enfoque avaliativo sobre a adequação dos processos educacionais e dos resultados da escolarização. Sob esse enfoque, tais resultados devem necessariamente abranger capacidades relativas ao respeito e valorização dos direitos humanos e à cidadania ativa, o desenvolvimento de condiçóes pessoais e sociais mais favoráveis ao exercício de todos os direitos em condiçóes de igualdade e, também, devem expressar a abertura ao pluralismo e a valorização da diversidade. Ao serem ampliadas e qualificadas as exigências quanto aos resultados educacionais, por sua vez, alteram-se as exigências quanto aos processos pedagógicos e mesmo sobre as condiçóes materiais e humanas para o seu desenvolvimento. Esse também é o enfoque adotado pelo atual Relator Especial da ONU para o Direito à Educação, Kishore Singh, para quem os direitos, princípios e objetivos educacionais, universalmente reconhecidos, "devem estar na base de todos os sistemas de educação. A aquisição de conhecimentos sobre os valores relativos aos direitos humanos deve estar à frente de qualquer discurso sobre a educação de qualidade”. (SINGH, 2012)

\section{Um marco normativo amplo sobre o conteúdo jurídico do direito à qualidade da educação básica}

A proposta de adoção do ponto de vista da teoria dos direitos fundamentais como princípios de Alexy (2008), a partir da qual concluímos que o direito à qualidade do ensino é um mandamento de máxima realização - não 
limitado ao direito positivo estabelecido em determinado contexto -, possibilita-nos estabelecer bases para a construção de uma teoria sobre o conteúdo jurídico amplo do princípio constitucional, coerente e articulada a toda a produção já consolidada sobre o conteúdo do direito humano à educaçáo.

Permite-nos, de um lado, não limitar nossa proposta de análise a uma determinada ideologia sobre o conteúdo do princípio constitucional, reconhecendo assim as diferentes acepçôes envolvidas nas disputas interpretativas e não excluindo, ao menos a priori, determinada concepção. Ao mesmo tempo, permite-nos assumir uma posição analítica comprometida com a realização ampla desse aspecto central do direito à educação, coerente com a preservação da força normativa dos direitos fundamentais contemporâneos, que obriga os Estados não apenas à realização de patamares mínimos, mas a adoção de medidas com o máximo de recursos disponíveis e até o pleno exercício desses direitos. Assim, a partir da sistemática da teoria dos princípios, o Estado deve atuar para assegurar progressivamente máxima qualidade do ensino, em condiçóes de máxima igualdade, liberdade, pluralismo, gestão democrática e valorização docente - os demais princípios do art. 206 da Constituição -, consideradas as limitaçôes fáticas e jurídicas existentes, e tendo como propósito o alcance dos objetivos amplos da educação como um direito humano.

Concluímos este artigo apresentando um marco conceitual normativo do princípio da qualidade do ensino no Brasil, construído a partir dos pressupostos já apresentados e da análise de alguns dos principais modelos de estruturaçáo do direito à qualidade da educaçáo básica em âmbito internacional. Referimo-nos tanto aos esforços recentes que vem sendo desenvolvidos por Kishore Singh (2012), como as proposiçóes de Unesco (2005) e Unicef (2000) nesse sentido. Em todas essas propostas, o direito à qualidade educativa é compreendido com base em um conjunto articulado de fatores, dimensóes e elementos escolares, profundamente influenciados por fatores extraescolares externos ao direito educacional.

Como apontam Abdeljalil Akkari, Beatriz Macedo e Sobhi Tawil (2012), há uma espécie de labirinto conceitual em torno da noção de qualidade do ensino, fruto da ausência de entendimento global sobre o tema. Tal incerteza em âmbito global, no entanto, não significa a inexistência de propostas de definiçáo da qualidade educativa relevantes para a compreensão do conteúdo normativo e, por conseguinte, do conteúdo jurídico do direito à qualidade.

Destacamos, nesse sentido, o estudo patrocinado pelo Unicef, denominado "Definindo Qualidade na Educação". (UNICEF, 2000) Publicado no contexto da Conferência de Dakar, em 2000, o trabalho apresentou uma abrangente revisão da literatura científica internacional. O objetivo era mapear e analisar estudos sobre experiências de promoção da qualidade da educação ao redor do mundo, recolhendo evidências sobre quais fatores influenciam ou determinam a garantia 
desse direito. Propóe, ao final, com base nessa revisáo, uma perspectiva ampla e compreensiva sobre que fatores precisariam ser observados quando se objetiva alcançar a qualidade educativa como um direito. Em linhas gerais, com base no enfoque de direitos, o Unicef identifica um considerável consenso internacional em torno da existência de fatores básicos de qualidade da educação, que envolveriam cinco dimensôes inter-relacionadas: estudantes, ambientes, conteúdo, processos e resultados, que são detalhadas em subdimensōes e apresentadas no estudo.

A Unesco, por sua vez, no Relatório de Monitoramento Global de Educação para Todos de 2005 (UNESCO, 2005), dedicado especificamente ao aprofundamento do monitoramento da Meta 6 de Dakar - garantia de qualidade -, propôs um marco conceitual específico. Ao mesmo tempo em que reconhece a diversidade de interpretaçóes sobre a qualidade nas diferentes tradiçóes educacionais, a Unesco assume a necessidade de sistematizar um entendimento global sobre a sua estrutura ampla, tomando como referências o enfoque de direitos humanos educacionais, a agenda política educacional em nível global e a necessidade de estabelecer indicadores de progresso. Com essas finalidades, caracteriza cinco dimensóes centrais que influenciam os processos básicos de ensino e aprendizagem: dimensão relativa às características dos alunos, dimensão de insumos facilitadores, dimensão de ensino e aprendizagem, dimensão de resultados e dimensão contextual.

Kishore Singh, Relator Especial para o Direito à Educação da ONU, dedicou seu informe anual de 2012 ao tema da qualidade, com o objetivo de traçar um balanço das normas, princípios e políticas nacionais e internacionais sobre o assunto. O objetivo de Singh (2012, p. 1) é

[...] promover a adoçáo de normas no plano nacional em que se estabeleça o direito a uma educação de qualidade, congruentes com o marco jurídico internacional dos direitos humanos e as iniciativas pertinentes adotadas nos planos nacional, regional e internacional.

O relator da ONU parte da constatação de uma crescente preocupação com a baixa qualidade da educação, que se reflete em uma nova vertente de juridificação. Reconhece que as discussôes relativas à qualidade da educação com frequência estão centradas nos baixos resultados de aprendizagem mensurados nos testes padronizados e que, assim difundidas, acabam por consolidar esses resultados e a forma de avaliá-los como um marco conceitual na definiçâo da própria noção de qualidade. Ampliar esse enfoque a partir da perspectiva de direitos humanos educacionais seria o grande desafio dos marcos normativos nacionais.

Diante desse quadro é que Singh propóe um "marco conceitual holístico" para a educação de qualidade, fundado em quatro pilares: 
[...] i) um nivel minimo de aquisição de conhecimentos, valores, capacidades e competências pelos estudantes; ii) infraestrutura, instalaçóes e ambientes escolares adequados; iii) um corpo docente bem qualificado; iv) uma escola aberta à participação de todos, em particular dos estudantes, seus progenitores e a comunidade. É pertinente destacar que a qualidade da educação náo pode ser alcançada sem que se proporcionem recursos suficientes para alcançar os imperativos da qualidade. (SINGH, 2012, p. 7) [grifo nosso].

Sobre o "nível mínimo de aquisição de conhecimentos, valores, capacidades e competências pelos estudantes", merece destaque a amplitude do conceito de resultados adotado pelo relator da ONU. Primeiramente, rejeita os pressupostos produtivistas que tendem a tomar as escolas como se fossem fábricas e, com isso, a medir a qualidade de seus resultados a partir do binômio insumo-produto. A crítica a esse enfoque se dá, dentre outras razóes, porque, ao destacar a eficiência econômica da educação, esse modelo tende a aceitar resultados (produtos) de mais baixa qualidade quando eles sejam mais eficientes do ponto de vista de seu custo de produção (insumos). Além disso, o produtivismo econômico aplicado à educação, nas hipóteses em que venha a valorizar o alcance de altos níveis de desempenho nos exames padronizados ou vestibulares, tenderá a eliminar todos os processos educacionais que, ainda que reconhecidamente relevantes para a realização do direito à educação em sua concepção ampla, signifiquem custos não justificáveis do ponto de vista dos resultados específicos e mensuráveis pretendidos. Dessa forma, essa lógica tende ainda a excluir física ou simbolicamente aqueles estudantes aos quais são atribuídas menores capacidades quanto à produção de resultados. Tal enfoque produtivista, portanto, é incompatível com a ideia de educação como direito humano, já que esses direitos "não podem se submeter a uma análise de benefício em função dos custos”. (SINGH, 2012, p. 18)

Com base no marco conceitual holístico sobre o direito à educação de qualidade e nos desafios relacionados à sua aplicação, Singh (2012) recomenda a todos os Estados que estabeleçam, ou reforcem seus marcos normativos próprios e suas políticas de promoção da qualidade. Isso demanda a adoção de normas e princípios de qualidade para todo o sistema educacional, considerando-se ainda que, segundo a Convenção da Unesco de 1960, "[os] Estados têm a obrigação de estabelecer um marco uniforme de normas de qualidade aplicável em todo o país". (SINGH, 2012, p. 8)

Tal marco normativo nacional deve, portanto, abarcar cada um dos pilares que constituem a definição do direito à qualidade educativa. Sua realização, contudo, depende de "uma mudança de paradigma nos gastos públicos em educação, para que correspondam aos imperativos de qualidade". (SINGH, 2012, p. 22) Essa mudança paradigmática passaria tanto pela determinaçáo das necessi- 
dades financeiras da educação a partir dos requisitos de qualidade - enfoque que no Brasil levou à ideia e ao cálculo do Custo Aluno-Qualidade (CAQ), já referida - quanto pelo financiamento justo e equitativo das escolas.

A partir dessas proposiçôes normativas gerais e do estudo da dimensão empírica de juridificação dos aspectos relacionados à qualidade do ensino no Brasil, entendemos que um marco conceitual para a descrição do conteúdo jurídico do direito à qualidade do ensino em nosso País deve abranger ao menos 7 (sete) dimensôes normativas: estudantes, ambiente escolar, condições de infraestrutura e insumos, conteúdos, processos educacionais relevantes, resultados e financiamento público.

Para testar e exemplificar a utilização desse marco normativo o aplicamos à análise conjunta das disposiçóes relacionadas a cada uma dessas dimensóes e respectivos elementos constitutivos no direito positivo brasileiro, especificamente na LDB, no ECA, na Lei do Piso Salarial do Magistério e na Lei do Fundeb. Por razóes de espaço, apresentamos abaixo um resumo, como resultado desse exercício:

\section{Tabela 1}

Dimensóes e elementos dos deveres estatais quanto à garantia do direito à qualidade da educaçáo básica - manifestação na legislaçáo

\begin{tabular}{|c|c|}
\hline Dimensão / Elementos Constitutivos & Manifestação na Legislação \\
\hline \multicolumn{2}{|c|}{ Dimensão 1 - Estudantes } \\
\hline $\begin{array}{l}\text { Saúde, nutrição e promoção de hábitos } \\
\text { de vida }\end{array}$ & LDB, $4^{\circ}$, VIII; LDB, 27, IV \\
\hline Desenvolvimento na primeira infância & LDB, 29,30 \\
\hline Frequência às unidades escolares & $\begin{array}{c}\mathrm{LDB}, 5^{\circ}, \S 3^{\circ} ; \mathrm{ECA}, 54, \S 3^{\circ} ; \mathrm{LDB}, 24, \\
\text { VI }\end{array}$ \\
\hline $\begin{array}{l}\text { Tempo disponivel para a escolarização } \\
\text { e relação com o mundo produtivo }\end{array}$ & LDB, art. $23, \S 2^{\circ} \mathrm{LDB}, 28$, caput, II \\
\hline Suporte educacional familiar & LDB, 12 , VI; ECA, 22 e 33 \\
\hline \multicolumn{2}{|c|}{ Dimensão 2 - Ambiente escolar } \\
\hline Segurança e disciplina escolar & LDB, 12, I; 13, II; ECA, 53, III \\
\hline $\begin{array}{c}\text { Prevenção e combate a maus-tratos, } \\
\text { exploração, intolerância ou } \\
\text { discriminação }\end{array}$ & $\mathrm{ECA}, 56, \mathrm{I} ; \mathrm{LDB}, 3^{\circ}, \mathrm{XII}$ \\
\hline \multicolumn{2}{|c|}{ Dimensão 3 - Condições de infraestrutura e insumos básicos } \\
\hline Infraestrutura escolar & LDB, $4^{\circ}, \mathrm{IX} ; \mathrm{LDB}, 25$ \\
\hline Acessibilidade física & LDB, $4^{\circ}$, VIII \\
\hline Materiais de ensino e aprendizagem & LDB, $4^{\circ}$, VIII; LDB, $79, \S 2^{\circ}$, III \\
\hline Recursos humanos & $\begin{array}{c}\text { LDB, } 61 \text { e } 62, \text { caput, } 62-\mathrm{A}, 64,65,67, \\
\S 1^{\circ} \text {, Lei } n^{\circ} 11.738 \text {, de } 2008 \text {, art. } 2^{\circ}, \S \\
4^{\circ}, \text { LDB }, 12 \text { a } 14\end{array}$ \\
\hline
\end{tabular}


continuação...

\begin{tabular}{cc}
\hline Dimensão / Elementos Constitutivos & Manifestação na Legislação \\
\hline \multicolumn{2}{c}{ Dimensão 4 - Conteúdos } \\
\hline Padrões básicos curriculares & LDB, $9^{\circ}$, IV; 26, caput ; LDB, 26-A \\
LDB, 10, V; 11, III; LDB, 28, caput, I e & III \\
Conteúdo regional e local & LDB, 12, I; 13, II; LDB, 59, I \\
Conteúdo escolar, comunitário e \\
adaptado
\end{tabular}

Letramento e conhecimentos matemáticos

LDB, 32, I; LDB, 36, § $1^{\circ}$, I e II

Desempenho mensurável em processo nacional de avaliação

LDB, $9^{\circ}, \mathrm{VI} ; \mathrm{LDB}, 87, \S 3^{\circ}$

Avaliação de desenvolvimento na educação infantil

LDB, 31, "i"; LDB, 31, V

Avaliação formativa e avaliação para progressão e certificação

LDB, 24, V, "a"; LDB, 32, § $2^{\circ}$

Objetivos amplos da educação:

cidadania, valores e direitos na e através da educação

Resultados relativos à inserção

profissional e aos benefícios

econômicos da educação para o indivíduo e a sociedade

Resultados em habilidades criativas e emocionais

LDB, 29; LDB, 35, III

Dimensão 7 - Financiamento Público

Custo Aluno Qualidade

Padrões básicos nacionais Incentivos
Lei $n^{\circ} 11.494$, de 2007, art. 38; LDB, 74 e 75

Lei $\mathrm{n}^{\circ} 11.738$, de 2008 , art. $4^{\circ}$ Lei $\mathrm{n}^{\circ} 11.494$, de 2007 , art. $7^{\circ}$, II, c/c Lei $n^{\circ} 11.738$, de 2008 , art. $4^{\circ}$, caput 
Construídas a partir de uma perspectiva dogmático-normativa sob o enfoque de direitos humanos educacionais, as dimensões e elementos do direito à qualidade náo se restringem às formas de juridificação efetivamente encontradas neste exercício, quando foram aplicadas à análise do direito positivo brasileiro. A aplicação prática desse modelo, portanto, deve ser entendida como um teste, com objetivo de validação e exemplificação, e não como fundamentação única dessas dimensōes e elementos. Seguindo a proposição básica deste trabalho, esses fatores devem ser interpretados da mesma forma que o princípio constitucional, ou seja, em seu sentido semântico mais amplo, não restrito ao conteúdo apreendido pelas normas específicas. Em sentido geral, também a cada uma de suas 7 (sete) dimensôes do direito à qualidade deve ser atribuído o objetivo de plena realização, com o máximo de recursos disponíveis.

\section{Considerações finais}

O direito à qualidade na educação básica é entendido, a partir do marco referencial desenvolvido com base na teoria dos direitos fundamentais como princípios de Alexy (2008) e nas disposiçóes normativas sobre o direito humano à educação, como o conjunto de condiçóes de infraestrutura, humanas e de insumos que permitem o desenvolvimento de processos educacionais relevantes e adaptados, assegurados gratuita e universalmente pelo Estado, objetivando garantir a todos a aprendizagem de conteúdos e habilidades necessários à realização dos direitos humanos na educação e através da educação. O objetivo do direito à educação é alcançar a igualdade de base em termos de sucesso escolar, com respeito à diversidade, ou seja, maximizar também a realização destes princípios. Nesse caminho, ambiente escolar, conteúdos e processos educacionais são partes estruturantes e inalienáveis do direito à qualidade e devem, assim, ser protegidos e realizados.

Complementa esse marco normativo sobre o conteúdo do princípio da qualidade da educação básica, ainda, a interação com os demais princípios do ensino inscritos no art. 206 da Constituição. Estes, conforme já analisamos, oferecem os melhores parâmetros para a delimitação e a interação na realização do conteúdo da qualidade.

As dimensóes e elementos que compóem o direito à qualidade devem ainda ser juridicamente protegidos com a preocupação de modulação quanto ao tipo de juridificação que mais se adeque ao paradigma de direitos humanos, evitando-se, principalmente, a excessiva juridificação e consequente burocratização de aspectos eminentemente político-pedagógicos, que devem compor o direito de autonomia relativa de escolas e professores. Ao direito infraconstitucional cabe delimitar e articular cada uma das dimensóes da qualidade, o que deve ser feito 
tanto através de normas jurídicas gerais, como no desenho jurídico-institucional das políticas públicas.

Esperamos, também, que a discussão e a proposição de marcos normativos amplos sobre o conteúdo jurídico do direito à educação de qualidade possam servir à revisão dos parâmetros de monitoramento desse direito e à estruturação de um sistema amplo de indicadores de realização, que venha a substituir os enfoques reducionistas que sobrevalorizam resultados padronizados em detrimento da maior parte dos demais elementos. Felizmente, há um conjunto de proposiçôes contra-hegemônicas em experimentação, com diferentes enfoques - experiências de "qualidade negociada" (FREITAS, 2005), Indicadores da Qualidade na Educação (AÇÃO EDUCATIVA et al., 2013) e Índice de Condições de Qualidade (GOUVEIA; SCHNEIDER; SOUZA, 2011) -, que deveriam servir de base para a constituição, em novo patamar, do Sinaeb, previsto no art. 11 do novo PNE.

Por fim, esperamos que a proposição de um marco normativo amplo sobre o direito à qualidade sirva de base a estudos empíricos, em nível nacional e subnacional. Estudos que venham a analisar como vem se configurando juridicamente, na prática, as políticas de promoção da qualidade, que efeitos determinadas técnicas de juridificação baseadas em incentivos produzem e como se opera o direito no controle burocrático de gestores, escolas e profissionais da educação. Essas não são questôes meramente teóricas, como vimos, mas estão na fronteira do direito à educação que vem sendo debatido no Legislativo e impulsionado nas políticas públicas.

\section{Notas}

1. Trabalho parcialmente baseado na tese de doutorado do autor, intitulada "Padrão de Qualidade do Ensino: Desafios Institucionais e Bases para a Construção de uma Teoria Jurídica", defendida em 2014 junto à Faculdade de Direito da USP.

2. Por juridificação deve se entender "a ampliação dos temas juridificáveis nos quadros da positivação do direito". (NEVES, 2011, p. 165) Enquanto fenômeno jurídico-social, é fruto da diferenciação e da complexificação dos arranjos sociais e da consequente diferenciação e fragmentaçấo do próprio direito.

3. O Estado Social e Democrático de Direito, para Jürgen Habermas (1999), é fruto do quarto impulso de juridificação do Estado Moderno, antecedido das fases representadas por Estado burguês da Europa Ocidental; Estado burguês de direito e Estado democrático de direito.

4. Aqui adotamos a concepção gramsciana sobre a forma de disputa por hegemonia política nas democracias capitalistas ocidentais, segundo a qual é na sociedade civil, parcela do Estado ampliado, que ocorrem as disputas de hegemonia, com evidentes influxos na construção dos direitos. Para o estudo dessa questão, indicamos: Gramsci; Coutinho, 2011.

5. "Direitos definitivos", nessa formulação, não devem ser tomados como direitos absolutos ou eternos, mas como direitos definidos em estrutura de regra após sopesamento legislativo ou judicial. Nova avaliação pode levar à sua alteração, produzindo-se daí um novo "direito definitivo".

6. A adoção da teoria dos direitos fundamentais como princípio na interpretação do art. 206 da Constituição requer cuidados, já que é necessário distinguir o uso do termo "princípio" na Cons- 
tituição de seu uso técnico, na forma proposta por Alexy (2008). Neste sentido, referido artigo contempla tanto regras (incisos IV, V, segunda parte, e VIII) como princípios (incisos I, II, III, $\mathrm{V}$, primeira parte, e VI). Esse aspecto, juntamente com o estudo do conteúdo de cada princípio constitucional do ensino e sua relação com o princípio da qualidade, é detidamente analisado em: Ximenes, 2014, p. 177 e ss.

7. Neste trabalho não estabelecemos distinção entre os conceitos de qualidade do ensino e padrão de qualidade do ensino, para uma análise sobre essa questáo indicamos: Ximenes, 2014, p. 153 e ss.

8. Destacamos, além do Pidesc, a Convenção da Unesco relativa à Luta contra a Discriminação no Ensino (1960), a Convenção Internacional sobre a Eliminação de todas as formas de Discriminaçãoo Racial (1966), a Convenção sobre a Eliminação de todas as formas de Discriminação contra as Mulheres (1979), a Convenção sobre os Direitos da Criança (1989) e a Convenção Internacional de Proteção às Pessoas com Deficiência (2007), todas incorporadas formalmente ao direito brasileiro.

\section{Referências}

AÇÃO EDUCATIVA et. al. Indicadores da Qualidade na Educação. São Paulo: Ação Educativa, 2013.

AFONSO, A. J. Avaliação educacional - regulação e emancipação. 4a ed. São Paulo: Cortez, 2009.

AKKARI, A.; MACEDO, B.; TAWIL, S. Au-delà du labyrinthe conceptuel: la notion de qualité en éducation. Recherche et Prospective en Education / Contributions thématiques. Paris : UNESCO, n. 2, p. 1-17, 2012.

ALEXY, R. Teoria dos direitos fundamentais. São Paulo: Malheiros, 2008.

BEISIEGEL, C. R. A qualidade do ensino na escola pública. Brasília: Líber Livro, 2006.

BUCCI, M. P. D. O conceito de política pública em direito. In: BUCCI, M. P. D. (Org.). Políticas públicas: reflexões sobre o conceito jurídico. Sáo Paulo: Saraiva, 2006, p. 1-49.

CARREIRA, D.; PINTO, J. M. R. Custo aluno-qualidade inicial: rumo à educação pública de qualidade no Brasil. São Paulo: Global; Campanha Nacional pelo Direito à Educação, 2007.

CURY, C. R. J. A constituição de Weimar: Um capítulo para a educação. Educ. Soc., Campinas, v. 19, n. 63, ago., 1998.

FREITAS, L. C. de. Qualidade negociada: avaliação e contra-regulação na escola pública. Educ. Soc., Campinas, v. 26, n. 92, p. 911-933, 2005.

FURTADO, M. G. Padrão de Qualidade do Ensino. In: RANIERI, N. B. S.(Coord.); RIGHETTI S. (Org.). Direito à educação: aspectos constitucionais. São Paulo: Edusp, 2009.

GENTILI, P.; SILVA, T. da (Orgs.). Neoliberalismo, qualidade total e educação: visóes críticas. 2a ed. Petrópolis: Vozes, 1995.

GOUVEIA, A.; SCHNEIDER, G.; SOUZA, A. Índice de condiçôes de qualidade educacional: metodologia e indícios. Estudos de Avaliação Educacional, São Paulo, v. 22, n. 48, p.115-136, jan./abr., 2011. 
GRAMSCI, A.; COUTINHO, C. N. (Org.). O leitor de Gramsci: escritos escolhidos 1916-1935. Rio de Janeiro: Civilização Brasileira, 2011.

HABERMAS, J. Teoría de la acción comunicativa. v. 2. Madrid: Taurus, 1999.

NEVES, M. A constitucionalização simbólica. São Paulo: Martins Fontes, 2011.

OLIVEIRA, R. P. de; ARAUJO, G. C. de. Qualidade do ensino: uma nova dimensão da luta pelo direito à educação. Rev. Bras. Educ., Rio de Janeiro, n. 28, abr., 2005.

PARO, V. Por dentro da Escola Pública. 3a ed. São Paulo: Xamá, 2000.

PIOVESAN, F. Igualdade, diferença e direitos humanos: perspectivas global e regional. In: SARMENTO, D. et al (Orgs.). Igualdade, diferença e direitos humanos. São Paulo: Lumen Juris, p. 47-76, 2008.

SILVA, V. A. da. Direitos fundamentais: conteúdo essencial, restriçôes e eficácia. 2a . ed. São Paulo: Malheiros, 2011.

SINGH, K. Medidas normativas para una educación de calidad. Informe del Relator Especial sobre el derecho a la educación (A/HRC/20/21). Genebra: ONU, 2012.

TOMASEVSKI, K. Human Rights Obligations in Education: the 4-A scheme. Nijmegen: Wolf Legal Publishers, 2006.

UNESCO. Relatório de Monitoramento Global 2005: o imperativo da qualidade. Brasília: Unesco, 2005.

UNICEF. Defining Quality in Education. Florence: Unicef, 2000.

VIEIRA, O. V. Do Compromisso Maximizador ao Constitucionalismo Resiliente. In: DIMOULIS, D. et al. Resiliência constitucional: compromisso maximizador, consensualismo político e desenvolvimento gradual. São Paulo: DIreito GV, p. 18-24, 2013. [Série Pesquisa Direito GV].

XIMENES, S. B. Direito à Qualidade na Educação Básica: teoria e crítica. São Paulo: Quartier Latin, 2014.

Recebido em 09 de dezembro de 2014. Aprovado em 27 de fevereiro de 2015. 